Núm. 28

ISSN: 2007-8870

\author{
http://revistainvestigacionacademicasinfrontera.com
}

Recibido el 25 de octubre de 2018 Dictaminado mediante arbitraje favorablemente 8 de diciembre de 2018

\title{
La actividad Física y el deporte como estilo de vida para la integración socio-laboral de empleados con discapacidad
}

\author{
MARÍA JULIA LEÓN BAZÁN ${ }^{1}$ \\ Universidad de Sonora, Unidad Centro \\ GRICELDA HENRY MEJIA ${ }^{2}$ \\ Universidad de Sonora, Unidad Centro \\ Nidia CAROLINA BARAHONA HERREJON ${ }^{3}$ \\ Universidad de Sonora, Unidad Centro
}

\begin{abstract}
RESUMEN
El trabajo de investigación se llevó a cabo bajo un enfoque metodológico descriptivo y transversal, basado en dos variables de estudio: Variable 1) Actividad Física y Deporte de trabajadores con discapacidades como generador de estilos de vida saludable y, Variable 2) Integración socio-laboral del trabajador con discapacidad. Para llevar a cabo el trabajo se investigación, se tomó como referencia a las empresas registradas en la Cámara Nacional de la Industria y la Transformación (Canacintra) de Hermosillo, Sonora, del giro industrial y que son incluyentes de acuerdo a la información presentada por la Secretaría de Economía de Sonora, la Secretaría del Trabajo en el Estado, en coordinación con el Servicio Nacional del Empleo (SNE Sonora) y DIF Sonora. El objetivo es determinar, a partir de las opiniones de personas con

\footnotetext{
${ }^{1}$ Departamento de Ciencias del Deporte y de la Actividad Física, Universidad de Sonora, Blvd. Luis Encinas y Rosales s/n, Colonia Centro, Hermosillo, Sonora Tel. (662) 2125936, correo electrónico: julia.leon@ unison.mx

${ }^{2}$ Departamento de Ciencias del Deporte y de la Actividad Física, Blvd. Luis Encinas y Rosales s/n, Colonia Centro, Hermosillo, Sonora, México Tel. (662)2125936,correo electrónico: grisyhenry@ hotmail.com

${ }^{3}$ Departamento de Ciencias del Deporte y de la Actividad Física, Blvd. Luis Encinas y Rosales s/n, Colonia Centro,

Hermosillo, Sonora, México Tel. (662)2125936.correo electrónico: nidiabara67@outlook.com
} 
discapacidad, como la actividad física y el deporte genera un estilo de vida saludable que facilita la integracion socio-laboral en la empresa. Los principales resultados muestran que las personas con discapacidad realizan actividad física y deporte como una medida para lograr estilos de vida saludables, lo que les ha permitido poder integrarse de forma social y profesionalmente en la empresa en la que trabajan.

Palabras Clave: Actividad Física, Deporte, Inclusión laboral, Estilo de vida.

\begin{abstract}
The research work was carried out under a descriptive, cross-sectional methodological approach, based on two study variables: Variable 1) Physical Activity and Sport of workers with disabilities as a generator of healthy lifestyles and, Variable 2) Integration partner-laboral of employees with disabilities. To carry out the research work, reference was made to the companies registered in the National Chamber of Industry and Transformation (Canacintra) of Hermosillo, Sonora, of the industrial sector and which are inclusive according to the information presented by the Secretariat of Economy of Sonora, the Secretary of Labor in the State, in coordination with the National Employment Service (SNE Sonora) and DIF Sonora. The objective is to determine, based on the opinions of people with disabilities, such as physical activity and the sport generates a healthy lifestyle that facilitates the socio - labor integration in the company. The main results show that people with disabilities perform physical activity and sport as a measure to achieve healthy lifestyles, which has allowed them to integrate socially and professionally into the company in which they work.
\end{abstract}

Key words: Physical Activity, Sport, Labor Inclusion, Lifestyle.

\title{
1. Introducción
}

La inclusión laboral en una empresa debe ser tomada como un factor para el crecimiento de la organización. Tener capacidades diferentes nunca debe de ser un factor para que una persona no sea contratada, tampoco su estatus social o las circunstancias adversas que pueden presentarse en su vida personal. Según datos del Instituto Nacional de Estadística y Geografía (INEGI, 2016), el 8\% de la población nacional mexicana tiene algún tipo de discapacidad. Y aunque la ley contempla a este porcentaje como candidatos elegibles para trabajar, con las mismas obligaciones y derechos laborales, sólo el 40.2\% de la población en edad para ser económicamente activa, recibe ingresos 


\section{http://revistainvestigacionacademicasinfrontera.com}

derivados del trabajo. El 28\% de las madres en México crían a sus hijos sin el apoyo de una pareja y su ingreso se convierte en el único sustento de la familia, y sólo el $43.4 \%$ tiene trabajo.

Las personas con discapacidad constituyen uno de los grupos más vulnerables con respecto a su integración al mercado laboral y hoy en día representan aproximadamente mil millones de personas, un $15 \%$ de la población mundial. Alrededor del 80 por ciento están en edad de trabajar. Sin embargo, su derecho a un trabajo decente, es con frecuencia denegado. Las personas con discapacidad y, en particular las mujeres, se enfrentan a enormes barreras actitudinales, físicas y de la información que dificultan el disfrute a la igualdad de oportunidades en el mundo del trabajo. En comparación con las personas sin discapacidad, las personas con discapacidad experimentan mayores tasas de desempleo e inactividad económica y están en mayor riesgo de una protección social insuficiente -la cual es clave para reducir la pobreza extrema- (OIT, 2015).

En el caso específico de México, el 5.1\% de la población tiene alguna discapacidad, es decir, 5.7 millones de personas y, de acuerdo a la Encuesta Nacional sobre Discriminación en México 2010 del Consejo Nacional para el Desarrollo y la Inclusión de Personas con Discapacidad (Conadis), el 27.4\% de la población con discapacidad refiere que la principal problemática a la que se enfrenta es el desempleo (Conadis, 2010).

Una de las tantas preocupaciones de una empresa que realiza inclusión laboral es la salud y la integración social asertiva de sus trabajadores, en los últimos años se han implementado programas de ejercicio físico en muchas empresas con el fin de incidir en el mantenimiento, la mejora de la salud y la integración social de sus trabajadores. La práctica de la actividad física y deporte en el ámbito laboral se define como aquella práctica en la que el empleador favorece y facilita directa o indirectamente que las personas empleadas en su puesto de trabajo puedan llevarla a cabo. Muchos estudios han demostrado que las personas físicamente activas padecen menos enfermedades que aquellas que tienen hábitos de vida más sedentarios y, la relación positiva entre la práctica de ejercicio físico, el rendimiento laboral y la integración social. Las personas que tienen interés por 
el desarrollo de hábitos de actividades físicas y deportivas mejoran a su vez su desarrollo personal y social.

A sí mismo, la motivación para la práctica de deporte en personas con discapacidad se convierte en una herramienta para gestionar mejor sus emociones y habilidades y mejoras en su autoestima que necesitan para desarrollar un estilo de vida saludable que se refleja en su desempeño personal mejorando su rendimiento laboral (Muñoz, Garrote y Sánchez, 2017). Por lo anterior, promover la buena salud en el ámbito laboral disminuye el ausentismo de los trabajadores y minimiza la pérdida de productividad. Resulta crucial seguir avanzando en el desarrollo de prácticas basadas en pruebas como es el caso de la actividad física y el deporte que se orienten, no solo a la mejora y medición de la calidad de vida individual de este colectivo, sino a la mejora de las prácticas organizacionales orientadas a la consecución de dicho fin. Partiendo de lo antes expuesto, el objetivo del presente trabajo de investigación es determinar, a partir de las opiniones de personas con discapacidad que laboran en empresas incluyentes, como la actividad física y el deporte genera un estilo de vida saludable que facilita la integracion socio-laboral en la empresa.

\section{Revisión de literatura}

En México, el primer esfuerzo nacional para la atención de personas con discapacidad se dio el 13 de Enero de 1977 con la creación del Sistema Nacional para el Desarrollo Integral de la Familia (DIF), cuya finalidad fue brindar asistencia social, como obligación del Estado, y en beneficio de la población marginada, a las personas con discapacidad, o las personas en desventaja social (DIF, 1977). Posteriormente en el año 2009, se presenta el Programa Nacional para el Desarrollo de las Personas con Discapacidad 2009-2012, creado por el Consejo Nacional para las Personas con Discapacidad (CONADIS), cuya misión fue conjuntar políticas de Estado y conducir la operación de estrategias en las instituciones del sector público en los tres órdenes de gobierno, para favorecer el desarrollo integral y la inclusión plena de las personas con discapacidad y sus familias en la vida social y productiva del país, con absoluto respeto a sus derechos humanos y libertades fundamentales.

En tiempos recientes la globalización ha acelerado y reforzado la necesidad de aceptar la diversidad en todos los ámbitos de la sociedad. La contratación de personas con discapacidad se reconoce cada vez más como un factor importante para mejorar la eficacia, productividad y éxito global de las empresas (CONAPRED, s.f.). Por ello, en agosto de 2014, el gobierno del Presidente Enrique 


\section{http://revistainvestigacionacademicasinfrontera.com}

Peña Nieto realiza reformas necesarias en México y desarrolla una política social incluyente, con un enfoque subrayado a la atención de los sectores más vulnerables de la sociedad mexicana, para la efectiva inclusión de este sector de la sociedad creando el Programa Nacional de Trabajo y Empleo para las Personas con Discapacidad 2014-2018 (PNTEPD), vigente a partir de abril del mismo año.

La incorporación al mercado de trabajo, ya no solo valora la posesión de un título académico, son otro tipo de competencias, las que ayudarán al trabajador a desarrollar de manera más eficaz su actividad socio laboral. Es importante tener en cuenta que, con el paso de los años, el mercado laboral está siendo más competitivo y complejo, por lo que el nivel de exigencia para nuestros trabajadores también va siendo cada vez más elevado (Cobas, 2015). Durante los últimos años, el Estado Mexicano ha implementado un sin número de acciones encaminadas a eliminar las barreras que enfrenta este sector de la sociedad, como es el caso de la última reforma a la Ley Federal de Trabajo, en donde se incluyó el concepto de trabajo digno o decente, y se prohíbe expresamente la discriminación por condiciones de discapacidad para el acceso, desarrollo y permanencia a un empleo (DOF, 2014). En 2013, se han visto resultados de mayor participación de los centros de trabajo en la convocatoria del Distintivo Empresa Incluyente "Gilberto Rincón Gallardo".

La importancia del deporte en personas con discapacidad ha sido analizada desde diferentes vertientes. Autores como (Segura, Martínez-Ferrer, Guerra, y Barnet, 2013) han analizado las creencias de actitud en el deporte sobre el deporte adaptado para personas con discapacidad y, también desde el estigma en las personas discapacitadas para la realización del mismo (Ferrante, 2014). La motivación es factor importante para la realización de prácticas deportivas en personas con discapacidad, a lo que autores como Torralba, Braz y Rubio (2014) y Chowdhury y Benson (2011). destacan la importancia de las condiciones físicas y de salud para practicar deporte. La discapacidad sigue siendo una barrera para el desarrollo social, personal, educativo y laboral de las personas que la padecen (OMS, 2011a, 2013). 
Pelayo (2012), menciona que una herramienta eficaz para el acceso al empleo está determinada por factores sociales tales como las relaciones interpersonales, sin embargo, esto no garantiza los mejores escenarios laborales para los jóvenes, debido a que orienta a empleos precarios y a una subvaloración del trabajo y la especialización. La misma autora menciona que, en referencia a los aspectos profesionales, existe una baja exigencia profesional por parte del mercado laboral, ya que hoy en día no es necesario tener un título universitario, hecho que justifica y perpetúa su precaria situación y el poco crecimiento personal y profesional de los jóvenes. Según Claes, Geert Van Hove, Vandevelde y Schalock (2012), los dominios bienestar emocional, físico y material reflejan el bienestar general de la persona; las relaciones interpersonales, la inclusión social y los derechos están referidos a la participación social; y los dominios desarrollo personal y autodeterminación remiten a la independencia personal.

Existen coincidencias en las dimensiones planteadas por los autores, donde uno de los dominios de calidad de vida coincidente es la autodeterminación, entendida como capacidad de decidir y elegir por sí mismo, siendo sus indicadores las metas, preferencias, decisiones, elecciones y autonomía de la persona. La autodeterminación basada en la aceptación e inclusión social, desempeña un papel mediador en el incremento de la calidad de vida, por lo que consideramos que al evaluar la autodeterminación de las personas con discapacidad estamos reflejando aspectos muy relevantes de su calidad de vida (Walker et al., 2011).

Hoy en día, la práctica de actividad física y deporte de forma regular está siendo un instrumento de cambio social en la gestión empresarial de la empresa (Fernández, 2008). La actividad física y el deporte es una herramienta útil para formar un equipo de trabajo saludable y activa, potenciando los valores de responsabilidad personal y colectiva en el desarrollo social logrando con esto una autonomía y una identidad de todos los miembros, también se produce un crecimiento personal y se fortalecen determinados valores como la responsabilidad, el compromiso, la solidaridad, el respeto, etc. Por lo tanto, un programa social deportivo dirigido por profesionales, genera situaciones de inclusión, promoviendo la educación, la salud y la organización de una comunidad, sin ningún tipo de discriminación (Gómez, Verdugo, Arias, Navas y Schalock, 2013). 


\section{http://revistainvestigacionacademicasinfrontera.com}

\section{Metodología}

\subsection{Diseño de la investigación}

Se estableció el objetivo del estudio, basándose en la información que era necesaria para determinar con base en las opiniones de las personas con discapacidad, como la actividad física y el deporte, genera un estilo de vida saludable que les facilita su integracion socio - laboral en la empresa. Este estudio se basa en una investigación de campo descriptivo con un enfoque de corte transversal, basado en dos variables: Variable 1) Actividad Física y Deporte de trabajadores con discapacidad como generador de estilos de vida saludable y, Variable 2) Integración socio-laboral de trabajadores con discapacidad.

\subsection{Elección y tipo de muestra}

Para clasificar a las empresas incluyentes se realizó una investigación de campo, tipo exploratorio acordado por los investigadores. Se tomó como criterio, a las empresas registradas en Canacintra, de Hermosillo, Sonora y que son incluyentes. De acuerdo a la información de la Secretaría de Economía de Sonora, la Secretaría del Trabajo en el Estado, en coordinación con el Servicio Nacional del Empleo (SNE Sonora) y DIF Sonora, existen en Hermosillo, Sonora un total de 800 empresas Pymes del sector industrial registradas en Canacintra, de las cuales, solo el 5\% son incluyentes, lo que equivale a una población total de 40 empresas que corresponden a la categoría elegida para el estudio. Por lo tanto, la fórmula utilizada para estimar el tamaño de la muestra fue mediante el muestreo aleatorio simple sin reemplazo, porque todos los elementos de la población tendrán la misma probabilidad de ser elegidos, obteniendo un total de 36 empresas. 


$$
\begin{gathered}
\mathrm{n}=\frac{\mathrm{N} \mathrm{Z}^{2} \mathrm{pq}}{(\mathrm{N}-1) \mathrm{E}^{2}+\mathrm{Z}^{2} \mathrm{pq}} \\
\mathbf{n}=\mathbf{3 6 . 3 1 3 4} \approx \mathbf{3 6}
\end{gathered}
$$

\subsection{Instrumento de recolección de datos}

Para poder realizar la comparación de las respuestas y por ende su categorización y generalización, se utilizará la entrevista abierta apoyada por un cuestionario estructurado donde se analizaron las dos variables de estudio: Variable 1) Actividad Física y Deporte de trabajadores con discapacidad como generador de estilos de vida saludable y, Variable 2) Integración socio-laboral de trabajadores con discapacidad. Para estimar la confiabilidad del instrumento aplicado, se llevó a cabo primeramente una prueba piloto con un mínimo de trabajadores con las características de la muestra elegida, que ayudara a realizar los ajustes necesarios en las mismas y así aunada a la prueba de fiabilidad realizada a través del programa SPSS alcancen un elevado grado de confiabilidad.

Para estimar la confiabilidad del instrumento aplicado, se hizo uso del programa IBM SPSS (Statistical Package for the Social Sciences), (Paquete Estadístico para las Ciencias Sociales, por sus siglas en inglés), para obtener el Alfa de Cronbach en cada una de los items, obteniendo en lo general un coeficiente de .900. Posteriormente, con la finalidad de detectar errores de diseño y la factibilidad del instrumento, se llevó a cabo una prueba piloto con un mínimo de empresas con las características de la muestra elegida, que ayudara a realizar los ajustes necesarios en las mismas y así aunada a la prueba de fiabilidad realizada a través del programa SPSS alcancen un elevado grado de confiabilidad. Las encuestas fueron aplicadas directamente a las personas con discapacidad dentro de las empresas seleccionadas, que permitió obtener información que sea verídica y confiable. La información recopilada, organizada y ordenada, será capturada en el programa estadístico SPSS, para su valoración e interpretación. 
Núm. 28

ISSN: 2007-8870

http://revistainvestigacionacademicasinfrontera.com

4. Presentación, análisis e interpretación de resultados

Se presentan a continuación los avances más relevantes basados en el objetivo central de esta investigación:

\subsection{Información general}

Imagen 1. Sexo

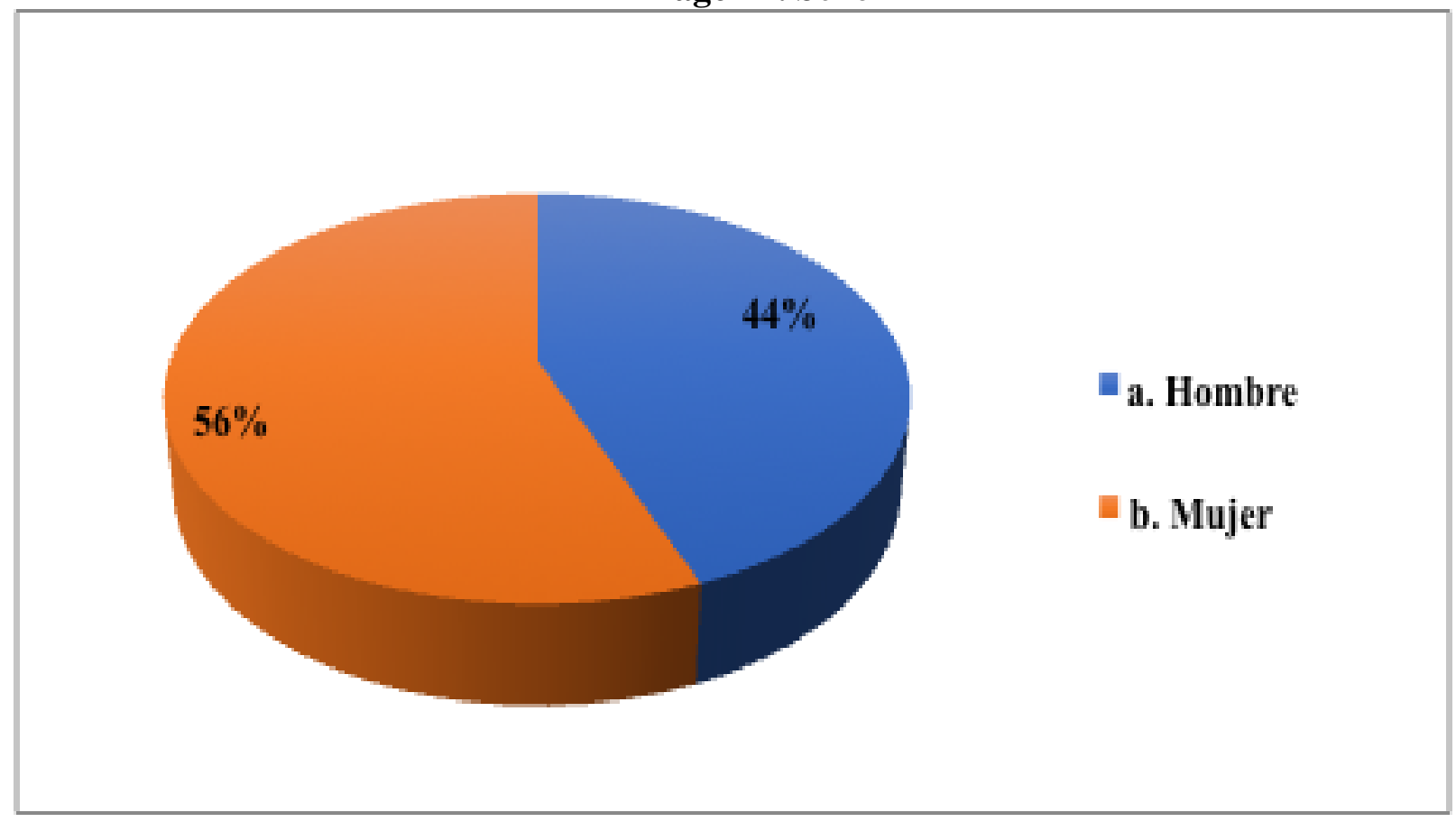

Fuente: Elaboración propia con base en los resultados obtenidos.

La Imagen 1, muestra que el $44 \%$ de los trabajadores con discapacidad son hombres y el $56 \%$ son mujeres. 
Imagen 2. Edad

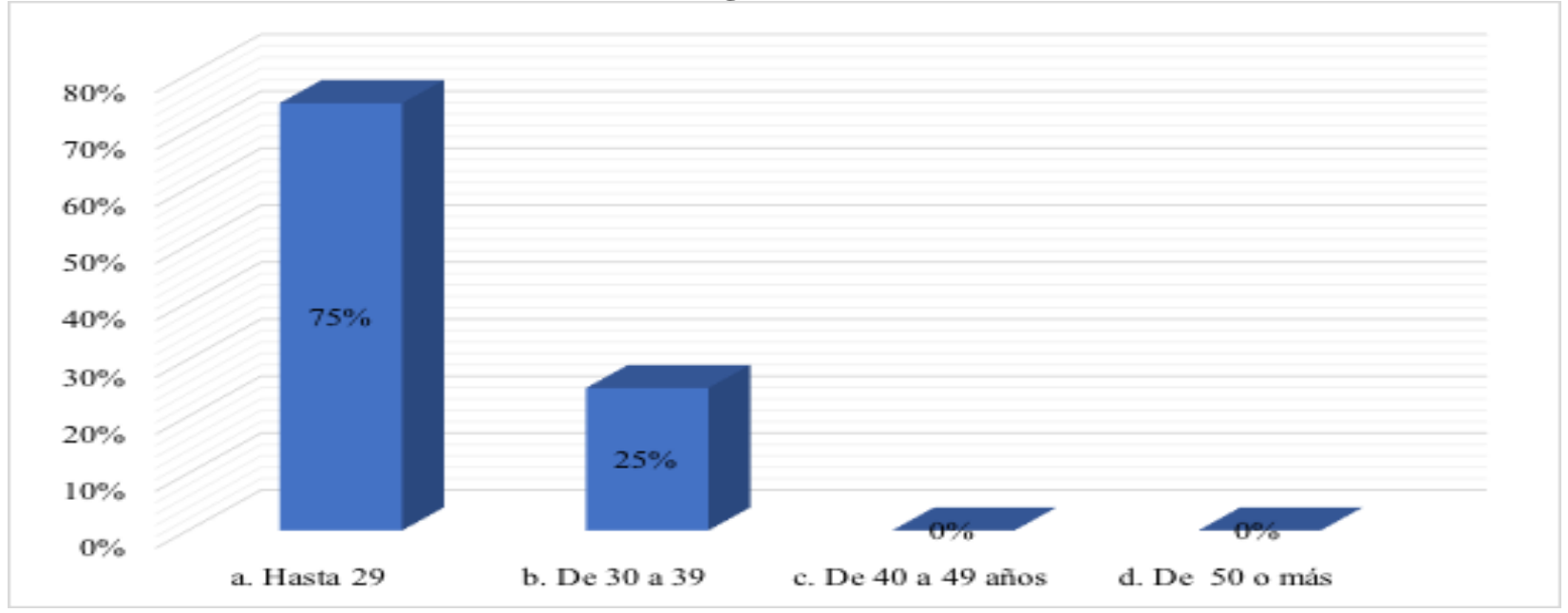

Fuente: Elaboración propia con base en los resultados obtenidos.

En la Imagen 2, se muestra que el 75\% de los trabajadores con discapacidad de la muestra analizada tienen una edad de hasta 29 años y el $25 \%$ de 30 a 39 años.

Imagen 3, Estado civil

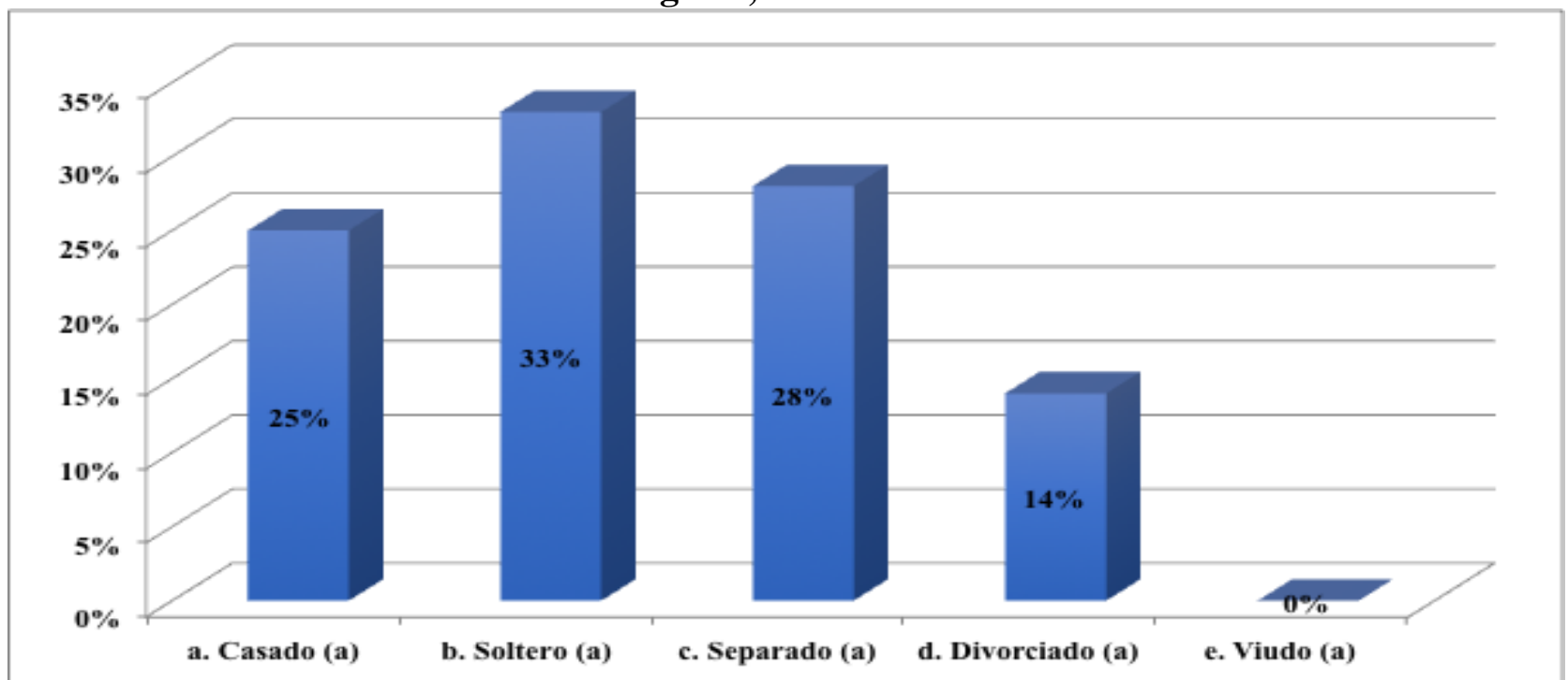

Fuente: Elaboración propia con base en los resultados obtenidos. 
Núm. 28

ISSN: 2007-8870

\section{http://revistainvestigacionacademicasinfrontera.com}

En la Imagen 3, se mestra que el $33 \%$ de los trabajadores son solteros, el $28 \%$ son separados, el $28 \%$ son separados y solo el $14 \%$ es divorciado.

Imagen 4, Nivel de estudios

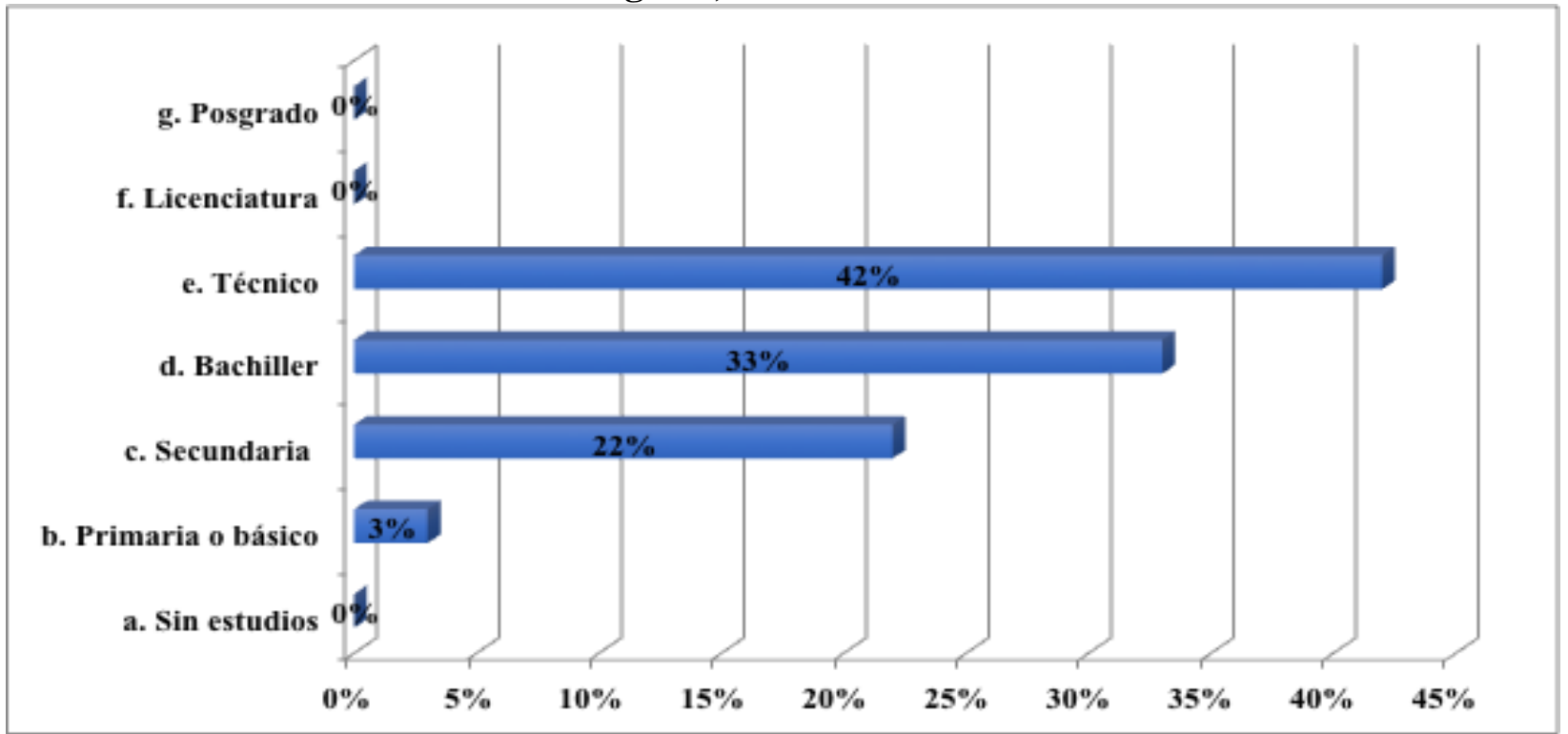

Fuente: Elaboración propia con base en los resultados obtenidos.

En la imagen 4, se muestra que el $42 \%$ tienen un nivel de estudios de técnico, el $33 \%$ nivel bachiller, el $22 \%$ cuenta con secundaria y el $3 \%$ tiene primaria o básico. 
Imagen 5, Tipo de contrato

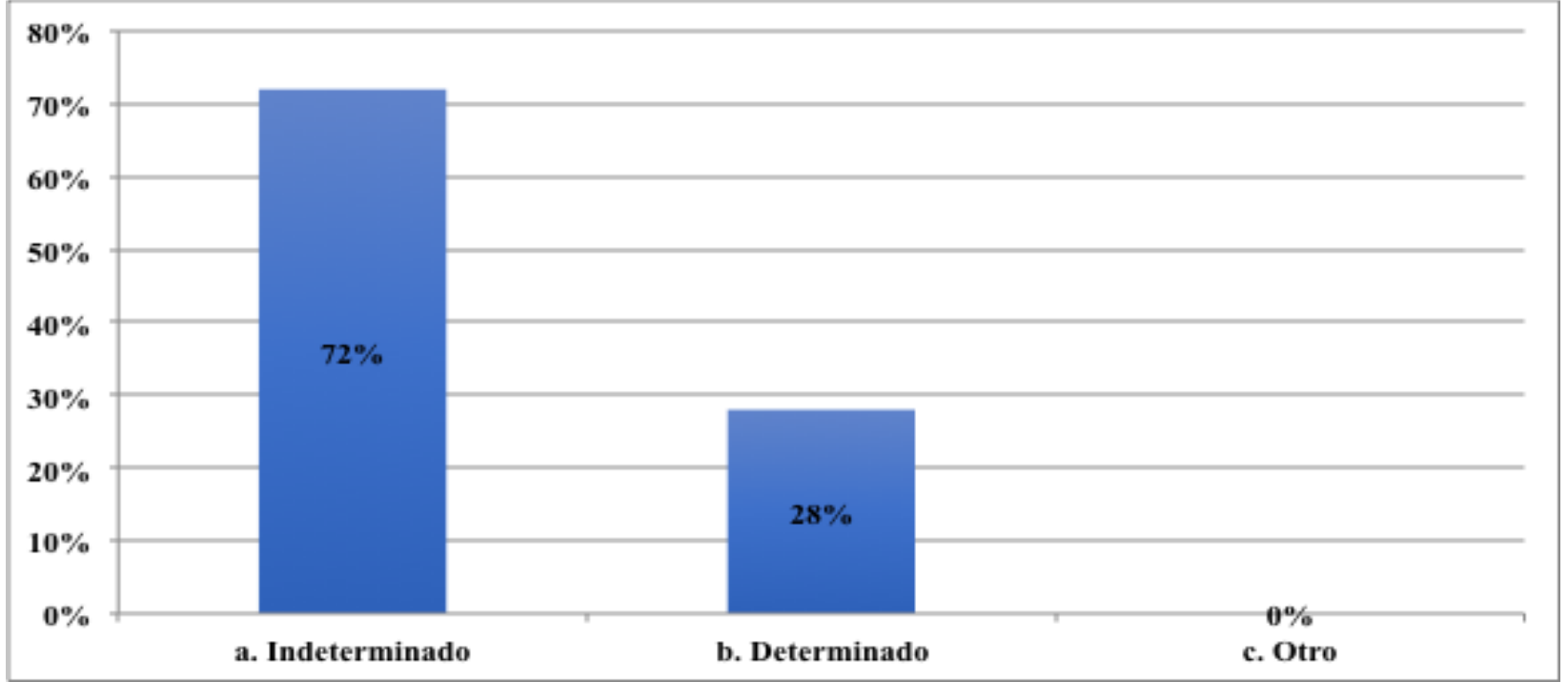

Fuente: Elaboración propia con base en los resultados obtenidos.

La imagen 5, muestra que el $72 \%$ de los trabajadores tienen un contrato indeterminado y el $28 \%$ determinado.

Imagen 6. Tipo de jornada

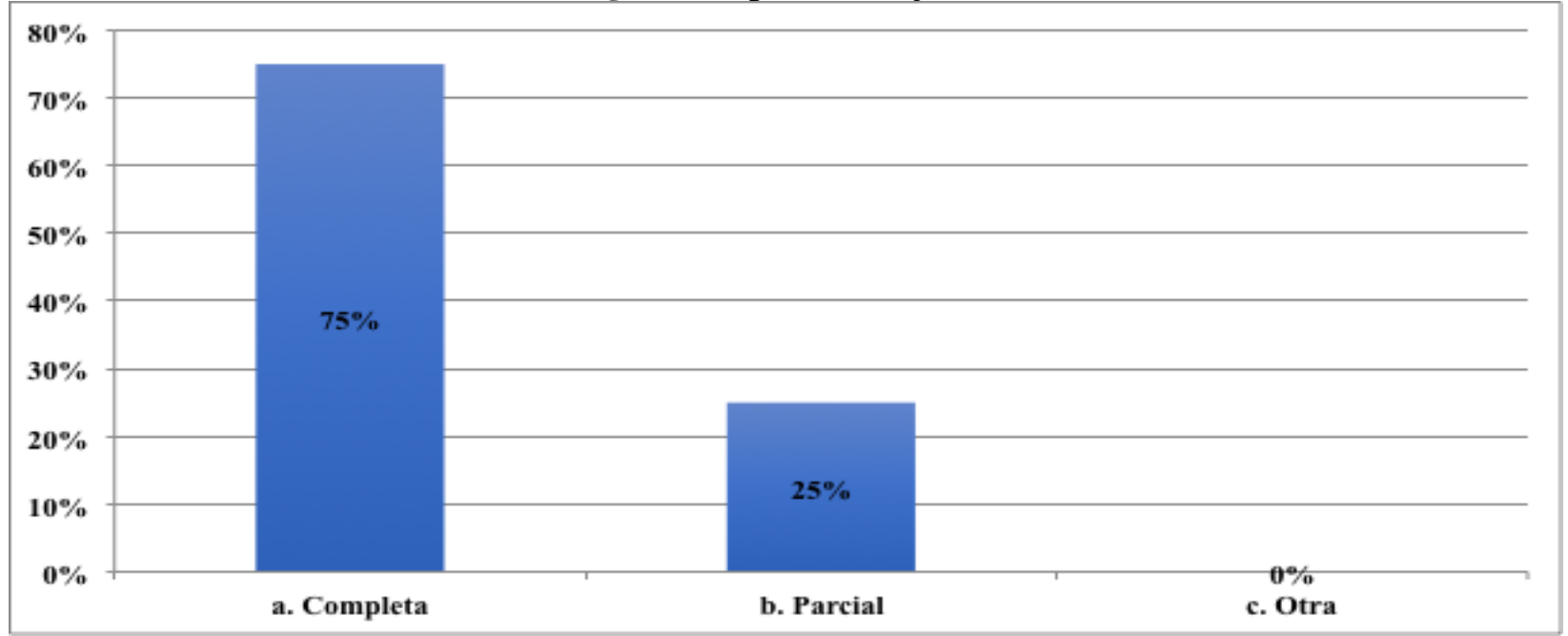

Fuente: Elaboración propia con base en los resultados obtenidos.

La Imagen 6, muestra que el $75 \%$ tienen una jornada completa y el 25\% cuenta con jornada parcial. 
Núm. 28

ISSN: 2007-8870

\section{http://revistainvestigacionacademicasinfrontera.com}

Imagen 7. Puesto dentro de la empresa

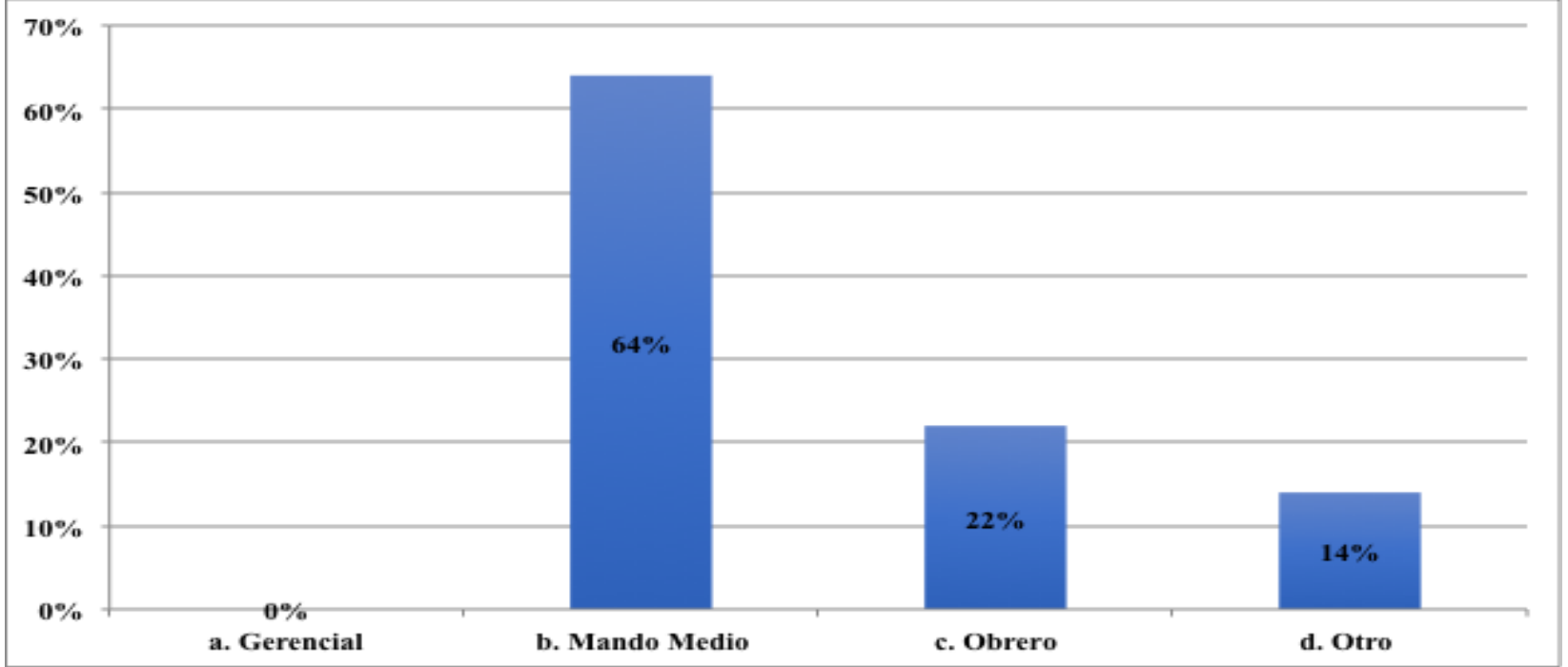

Fuente: Elaboración propia con base en los resultados obtenidos.

La Imagen 7, muestra que el 6\% de los trabajadores con discapacidad tienen puesto de mando medio en la empresa, el $22 \%$ son obreros y el $14 \%$ otros. 
Imagen 8. Tipo de discapacidad

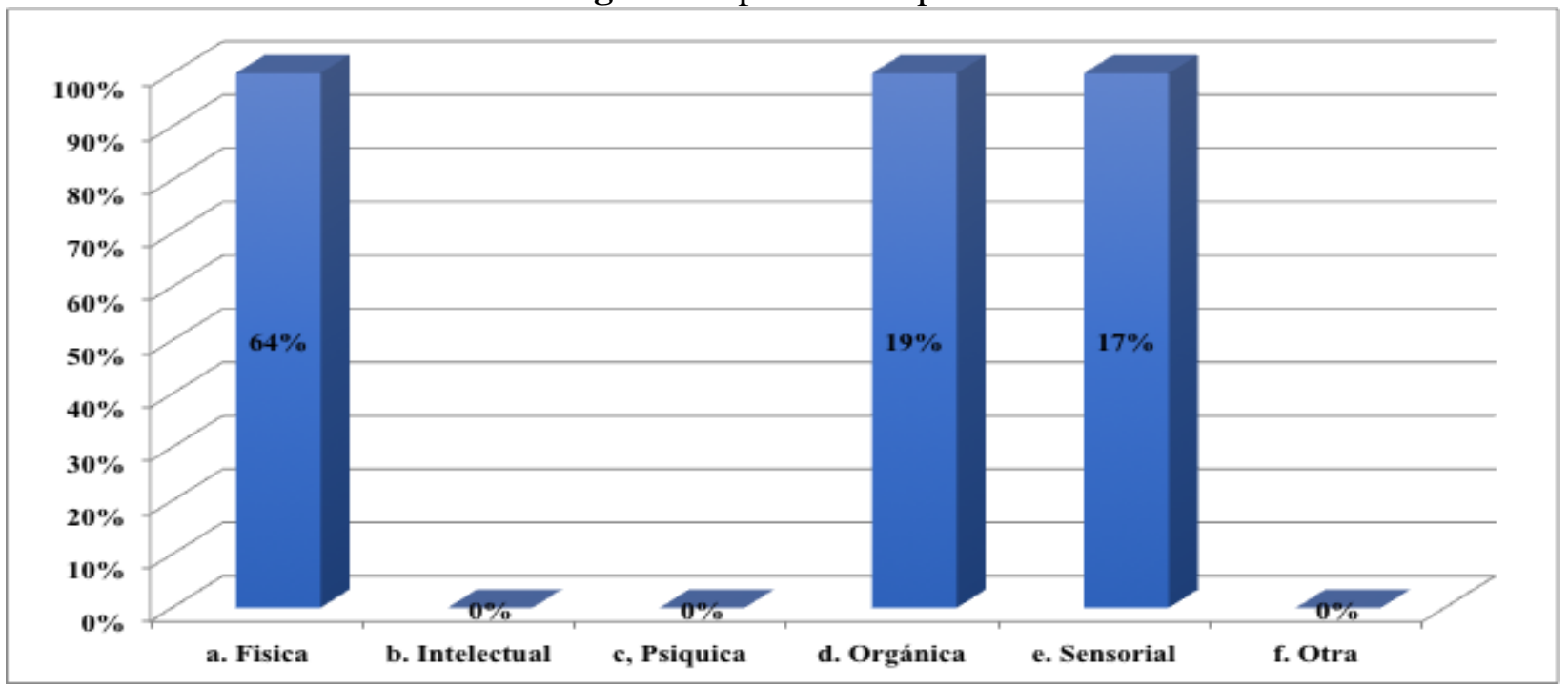

Fuente: Elaboración propia con base en los resultados obtenidos.

En la imagen 8, se muestra que el 64\% tiene una discapacidad física, el 19\% orgániza y el 17\% sensorial.

Imagen 9. Grado de discapacidad

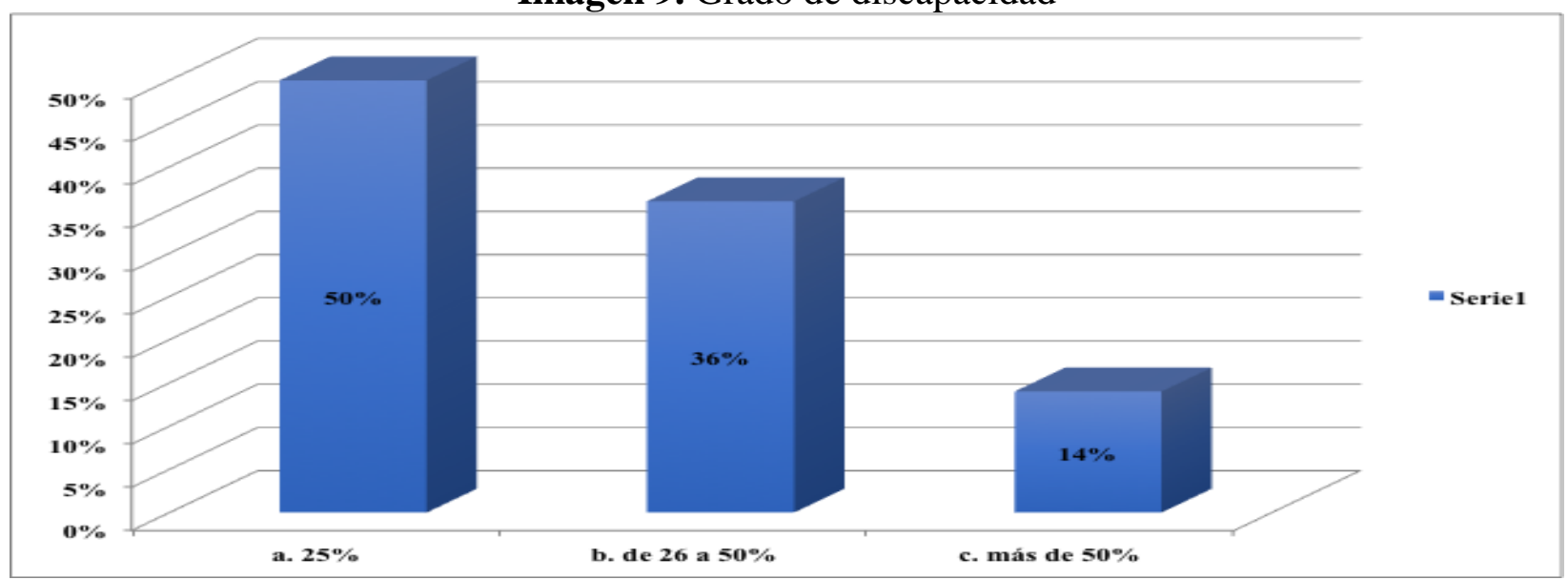

Fuente: Elaboración propia con base en los resultados obtenidos.

En la Imagen 9, se muestra que el grado de discapacidad es de un $25 \%$ un total del $50 \%$ de los trabajadores, de 26 a $50 \%$ un total de $36 \%$ y con más del $50 \%$ un total de $15 \%$ de los trabajadores. 
http://revistainvestigacionacademicasinfrontera.com

\subsection{Variable 1; Actividad física y deporte como generador de estilos de vida saludable}

Imagen 10. Interés por la actividad física y el deporte

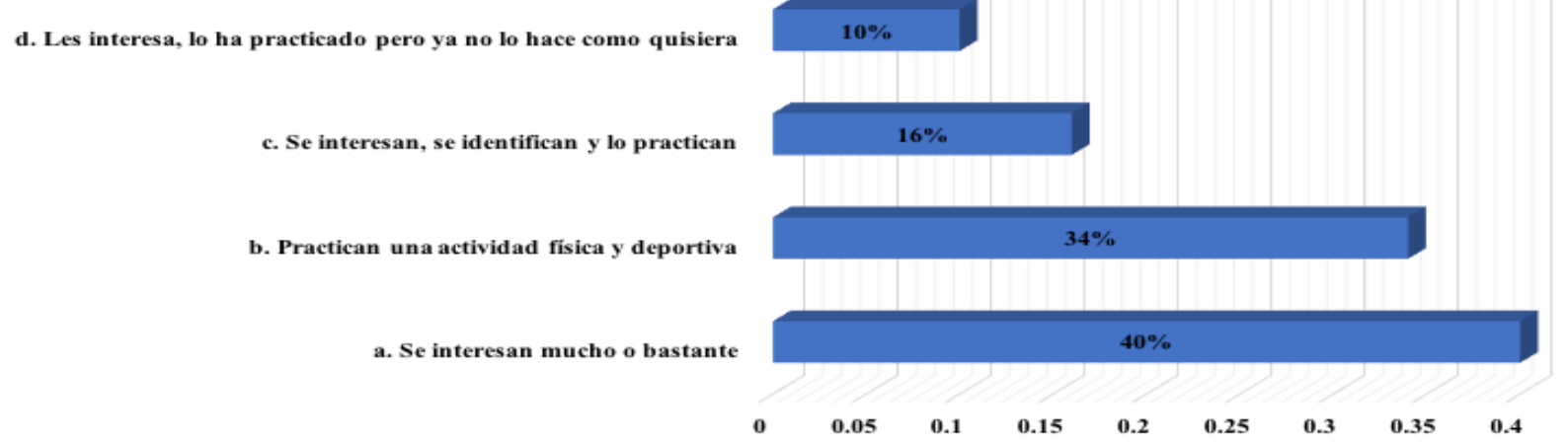

Fuente: Elaboración propia con base en los resultados obtenidos.

Considerando el deporte en todas sus formas (juego, espectáculo, ejercicio físico y diversión, independientemente que los sujetos lo practiquen o no), en la Imagen 10, se muestra que el $40 \%$ de los trabajadores se interesan mucho o bastante por el deporte, el $24 \%$ practican una actividad física y deportiva, el $16 \%$ se interesan, identifican y lo practican y el $10 \%$ le interesa, lo ha practicado, pero ahora ya no lo practica. 
Imagen 11. Frecuencia con la que realiza actividad física y deporte

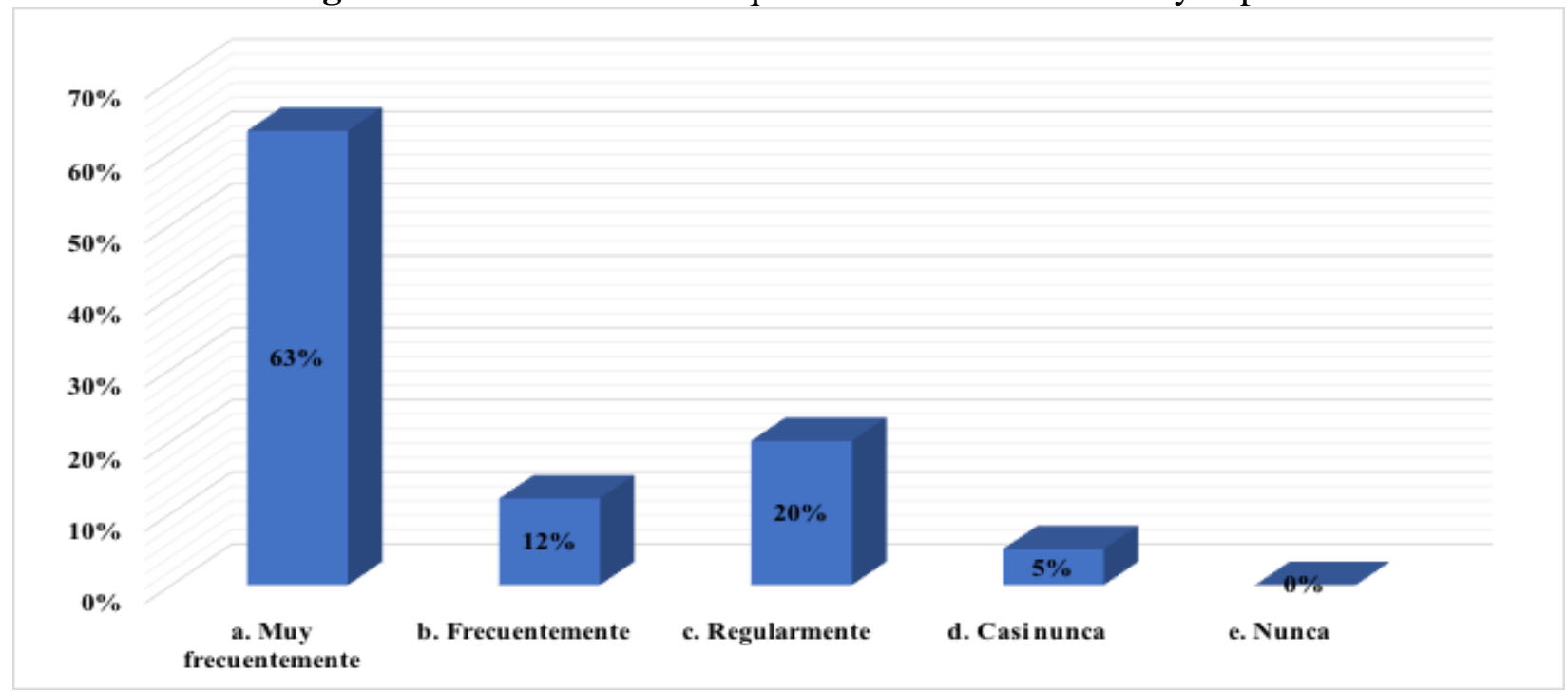

Fuente: Elaboración propia con base en los resultados obtenidos.

La Imagen 11; muestra que el 63\% de los trabajadores con discapacidad de la muestra analizada realiza muy frecuentemente actividad física y deporte, el $28 \%$ la realiza regularmente, el $12 \%$ frecuentemente y el 5\% casi nunca. Los resultados muestran que este tipo de trabajador usa con regularidad la actividad física y deporte.

Imagen 12. Motivos por los que practican la actividad física y el deporte

b. Quieren conocer a personas nuevas

d. Otros

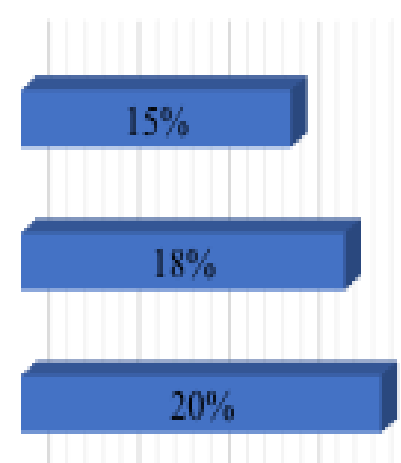

a. Estar en buena forma fisica

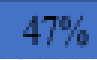

\section{$\begin{array}{lllllllllll}0 & 0.05 & 0.1 & 0.15 & 0.2 & 0.25 & 0.3 & 0.35 & 0.4 & 0.45 & 0.5\end{array}$}

Fuente: Elaboración propia con base en los resultados obtenidos. 


\section{http://revistainvestigacionacademicasinfrontera.com}

La Imagen 12; muestra que de acuerdo al $47 \%$ de los trabajadores discapacitados de la muestra analizada, los motivos principales por los que practican deporte son porque quieren estar en buena forma física, el $20 \%$ quieren conocer a personas nuevas, el $18 \%$ porque les sube la autoestima y el $15 \%$ otros motivos fundamentales que son: mantener su peso para tener buena imagen, les gusta estar con amigos, porque les gusta hacer esta actividad, les hace feliz, les gusta estar con otros a los que también les interesa esta actividad, quieren mantener su fuerza física para vivir de forma saludable, mantener su nivel de habilidad actual, disfrutan con esta actividad.

Imagen 13. Hábito deportivo

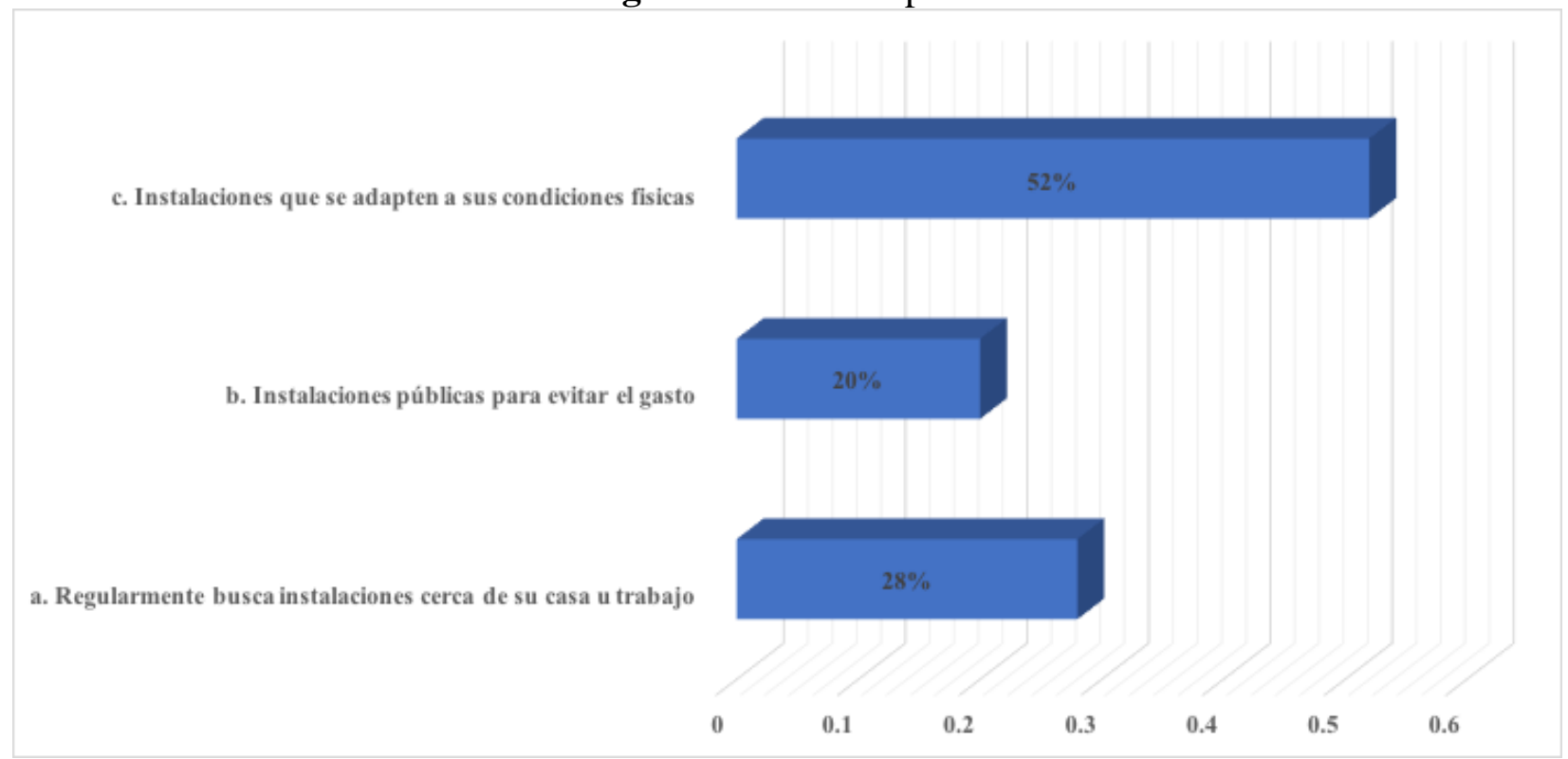

Fuente: Elaboración propia con base en los resultados obtenidos.

En la Imagen 13, se muestra que el 52\% tiene como hábito buscar instalaciones que se adapten a sus condiciones físicas, el $28 \%$ busca regularmente que las instalaciones estén cerca de su casa y el $20 \%$ instalaciones públicas para evitar el gasto. Los resultados muestran que el hábito principal 
es hacer la actividad física y deporte en un lugar acorde a sus condiciones físicas, independientemente del lugar donde las realice.

Imagen 14. Actividad física y estilo de vida

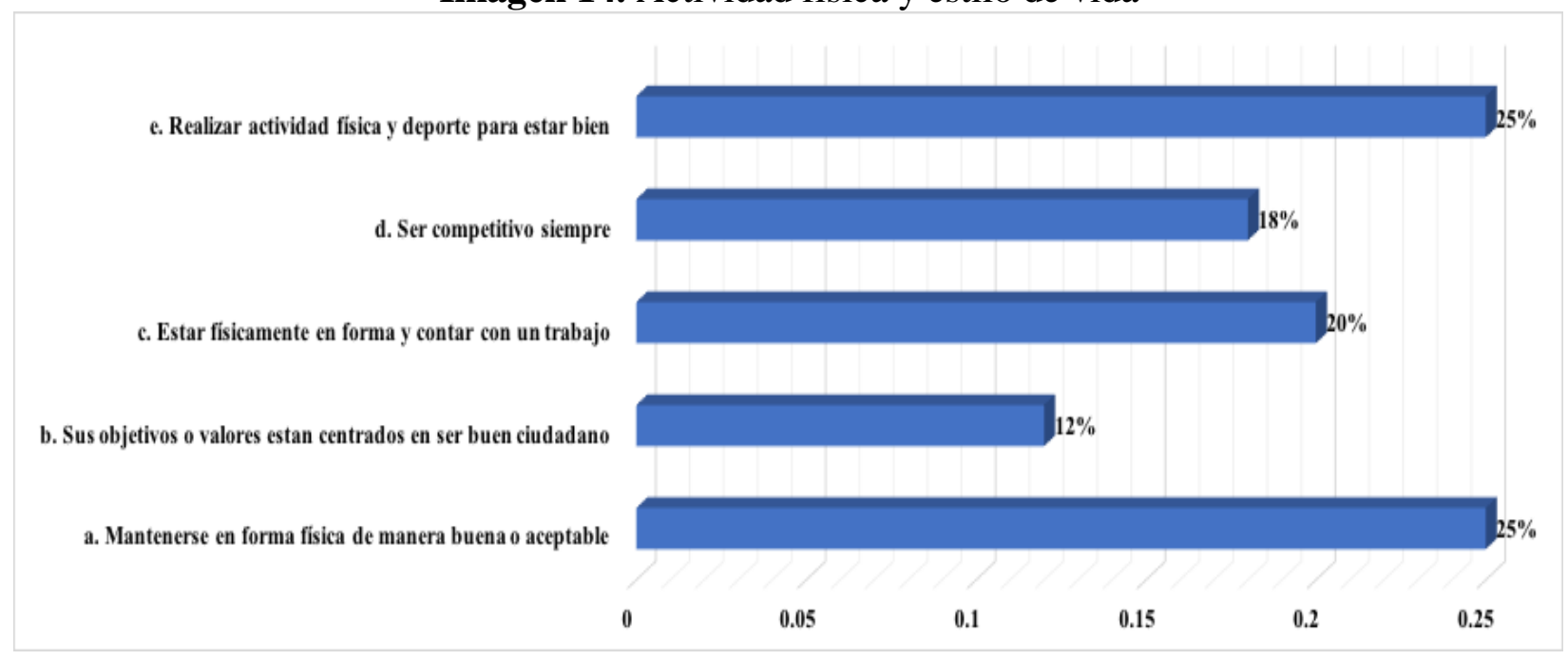

Fuente: Elaboración propia con base en los resultados obtenidos.

La Imagen 14, muestra que para el $25 \%$ de estos trabajadores, centran la actividad física y estilo de vida para estar bien y mantenerse en forma física de manera buena o aceptable, el $20 \%$ para estar físicamente en forma y contar con un trabajo, el 18\% para ser competitivo siempre y el $12 \%$ su objetivo o valores están centrados en ser buen ciudadano. 
http://revistainvestigacionacademicasinfrontera.com

\subsection{Variable 2; Integración socio-laboral de trabajadores con discapacidad}

Imagen 15. Se valora mi contribución al desarrollo de la empresa

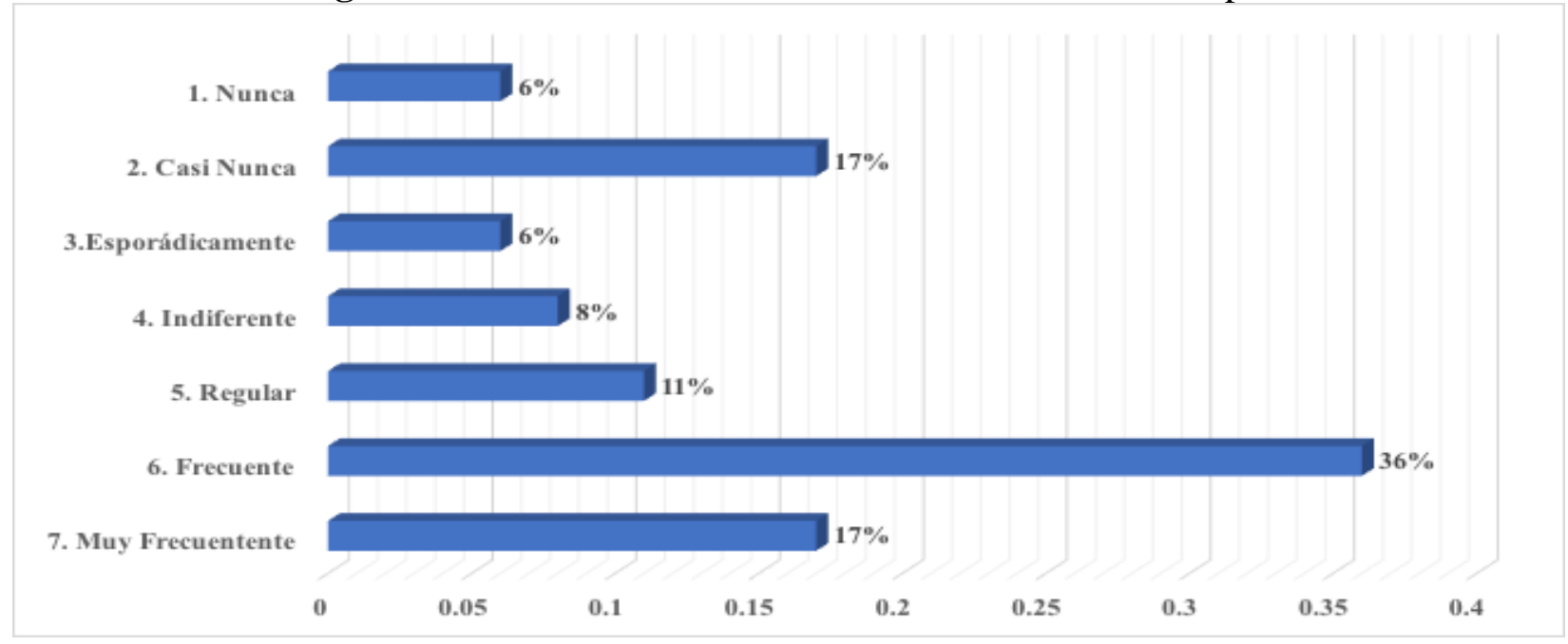

Fuente: Elaboración propia con base en los resultados obtenidos.

La Imagen 15, muestra que el 36\% de la muestra analizada menciona que la empresa valora de forma frecuente su contribución al desarrollo de la empresa, hay una coincidencia de resultados del $17 \%$ que menciona que casi nunca o muy frecuentemente lo hace, el $11 \%$ menciona que regularmente lo hace, el $8 \%$ le es indiferente y otra igualdad del $6 \%$ menciona que nunca o esporádicamente lo hace. Los resultados muestran que, al parecer para el trabajador es importante se le reconozca cuando su trabajo contribuye al desarrollo de la empresa. 
Imagen 16. La empresa considera mis objetivos y valores

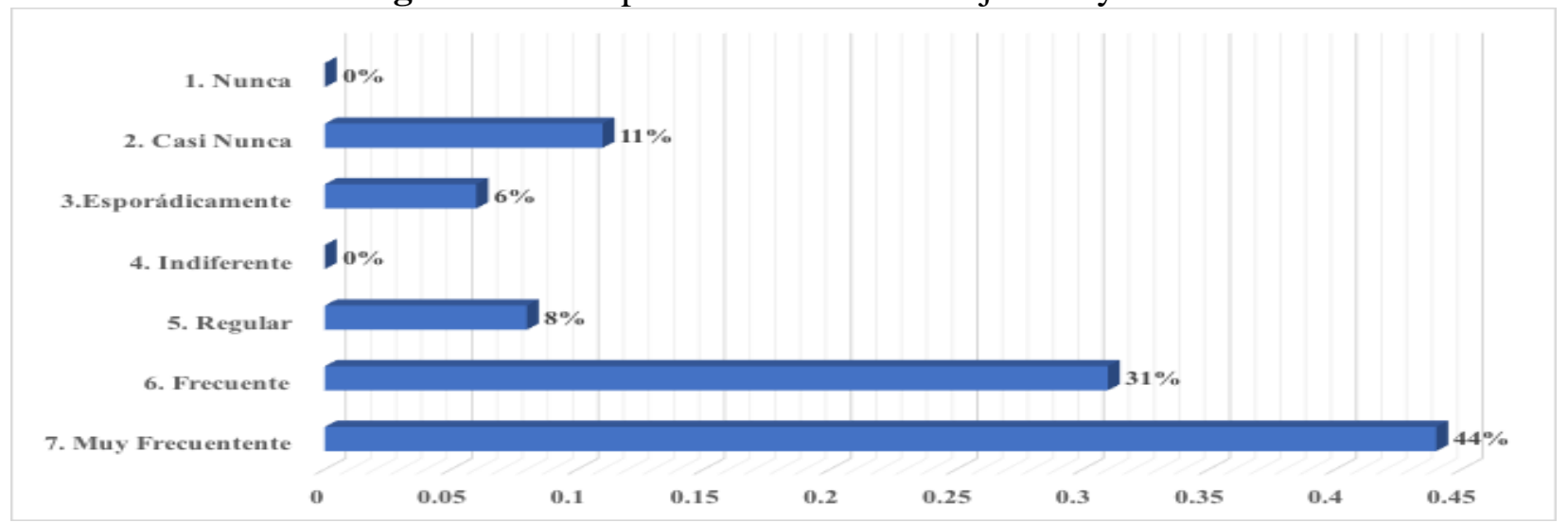

Fuente: Elaboración propia con base en los resultados obtenidos.

La Imagen 16, muestra que el $44 \%$ de la muestra analizada opina que muy frecuentemente la empresa considera sus objetivos y valores, el $31 \%$ opina que frecuentemente, el $11 \%$ casi nunca, el $8 \%$ regularmente y el $6 \%$ esporádicamente. Los resultados muestran que, al parecer estos trabajadores valora la consideración que da la empresa a sus objetivos y valores.

Imagen 17. La empresa está dispuesta a ayudarme para que realice mi trabajo lo mejor posible

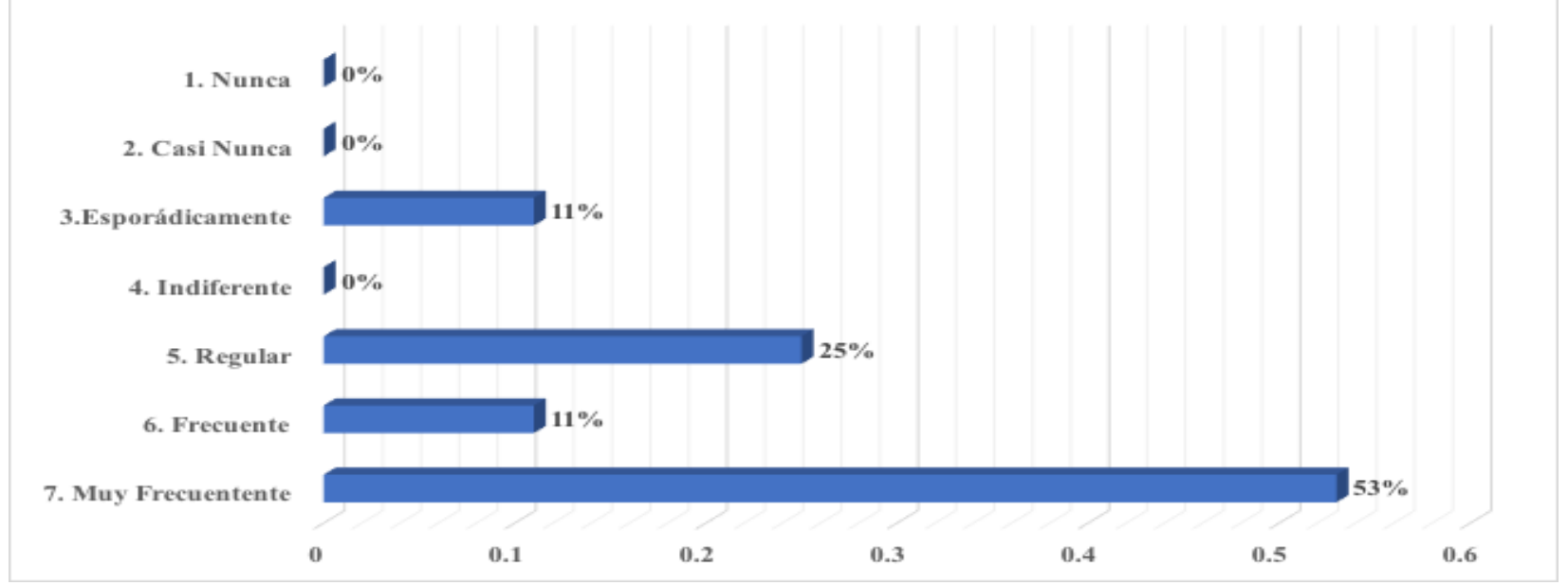

Fuente: Elaboración propia con base en los resultados obtenidos. 


\section{http://revistainvestigacionacademicasinfrontera.com}

En la Imagen 17, los resultados del 53\% hacen ver que, de acuerdo a las opiniones de los trabajadores con discapacidad, muy frecuentemente la empresa está dispuesta a ayudarle para que realice su trabajo lo mejor posible, el $25 \%$ opina que regularmente lo hace, hay una igualdad del $11 \%$ que menciona que frecuentemente o esporádicamente lo hace. Los resultados permiten deducir que, al parecer la empresa se preocupa por que este tipo de trabajadores realice lo mejor posible su trabajo.

Imagen 18. La empresa se interesa por mi satisfacción en el trabajo

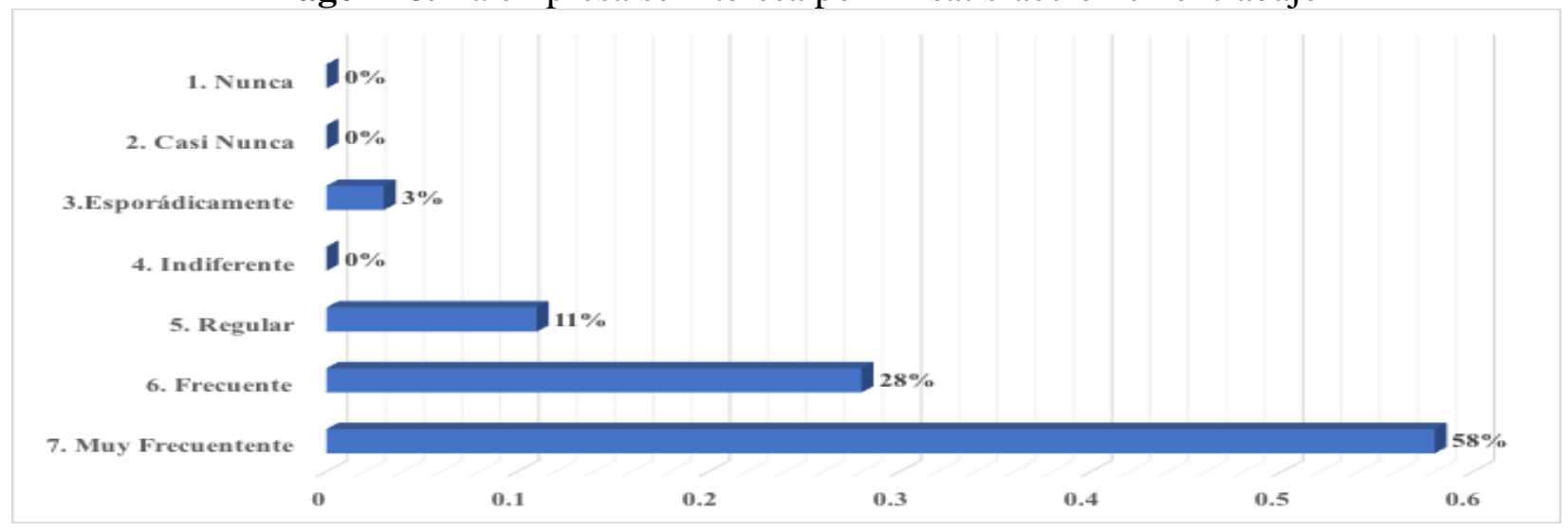

Fuente: Elaboración propia con base en los resultados obtenidos.

En la Imagen 18, se muestra que el $58 \%$ de los sujetos de estudio opinan que muy frecuente la empresa se interesa por su satisfacción en el trabajo, el $28 \%$ opina que frecuentemente lo hace, el $11 \%$ opina que regularmente y el $3 \%$ esporádicamente. Los resultados muestran que, al parecer para la empresa es importante que este tipo de trabajadores se sienta satisfecho con el trabajo que realiza dentro de la empresa. 
Imagen 19. La empresa se preocupa por que mi trabajo sea lo más interesante posible

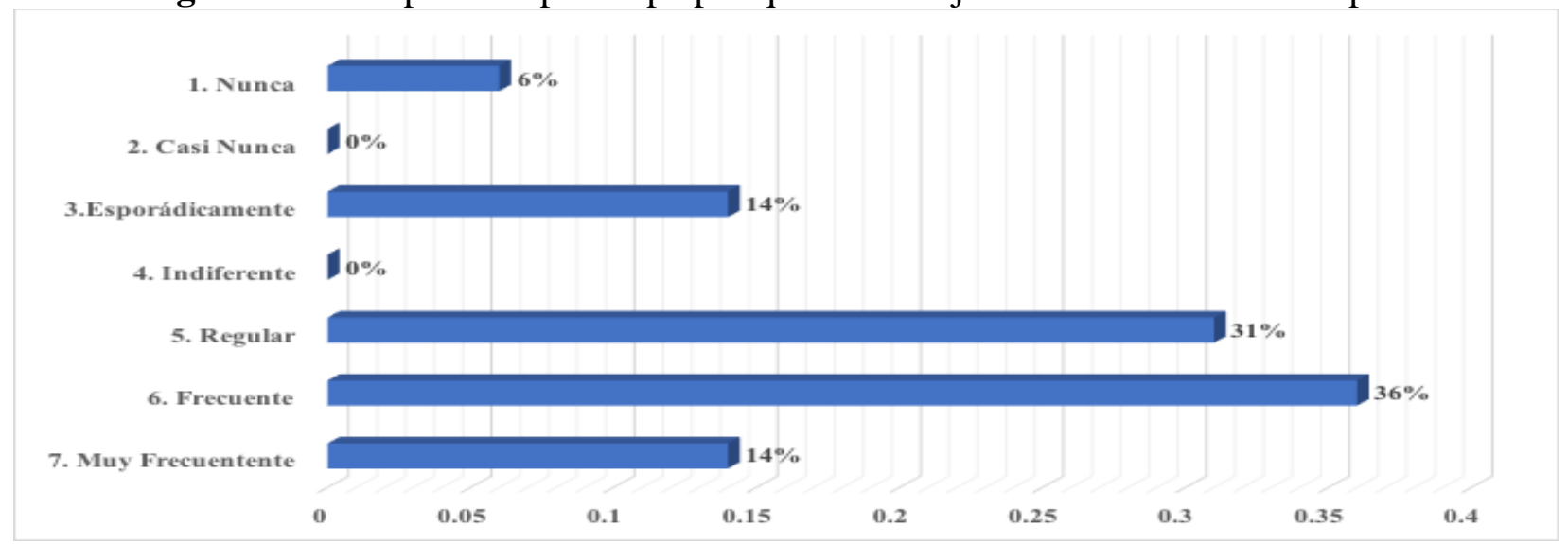

Fuente: Elaboración propia con base en los resultados obtenidos.

La Imagen 19, muestra que de acuerdo al 36\% de los sujetos del estudio, la empresa se preocupa muy frecuentemente porque su trabajo sea lo más interesante posible, el $31 \%$ opina que regularmente lo hace, hay una igualdad de respuesta del $14 \%$ que opina que muy frecuentemente o esporádicamente lo hace y el $6 \%$ opina que nunca lo hace. Con base en las opiniones de los trabajadores con discapacidad, la empresa busca que su trabajo sea interesante, posiblemente para lograr que el trabajador de lo mejor de sí mismo en su trabajo dentro del puesto.

Imagen 20. La empresa se preocupa por su satisfacción en el trabajo

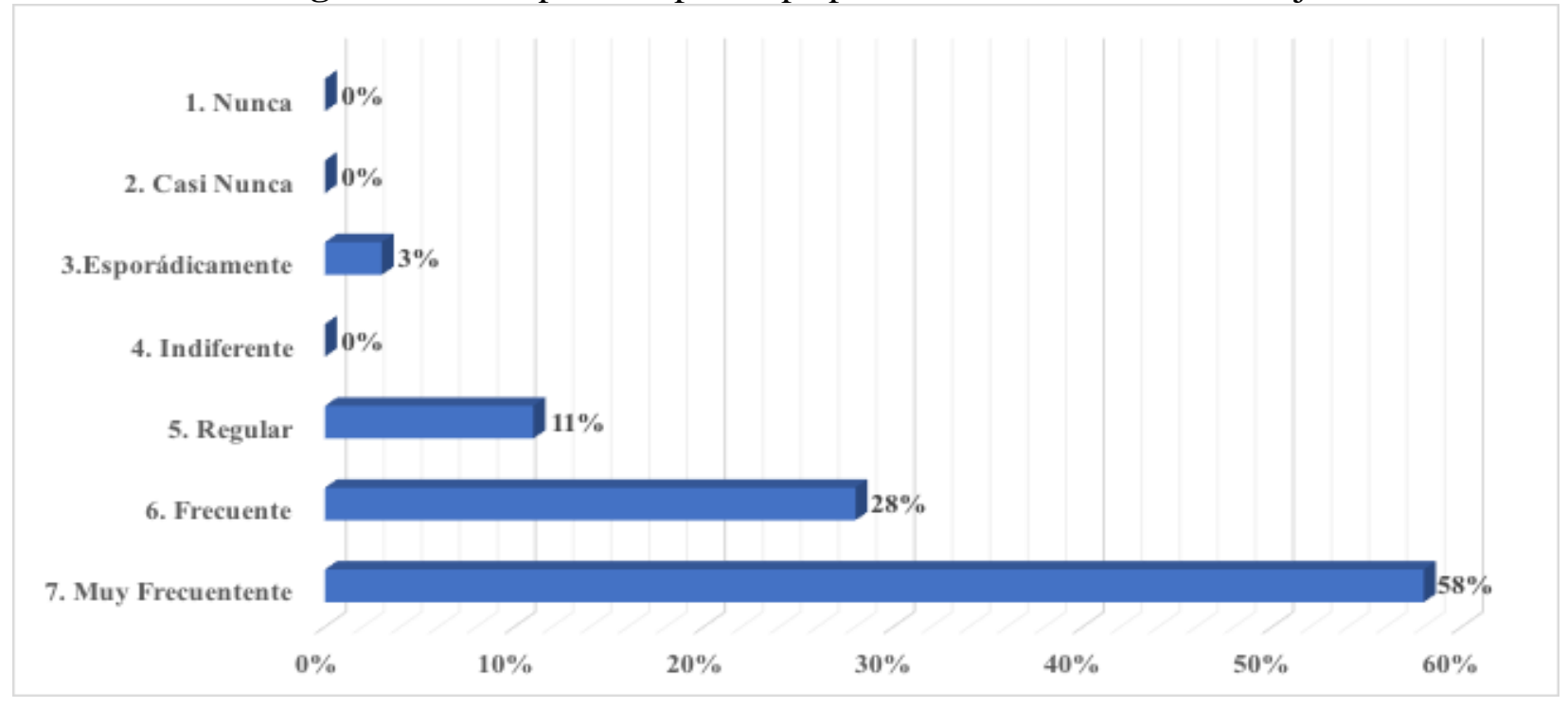

Fuente: Elaboración propia con base en los resultados obtenidos. 


\section{http://revistainvestigacionacademicasinfrontera.com}

En la Imagen 20, el 58\% de los sujetos de estudio, opinan que la empresa, muy frecuentemente se preocupa por su satisfacción en el trabajo, el $28 \%$ opina que frecuentemente lo hace, el 11\% opina que regularmente y el 3\% esporádicamente. Los resultados muestran que de acuerdo a las opiniones de los trabajadores con discapacidad, la empresa se preocupa por que se sientan satisfechos en lo que hacen, esto posiblemente les permite lograr que el empleado sea mas productivo.

\section{Conclusiones e implicaciones sociales y empresariales}

Las personas con discapacidad constituyen uno de los grupos más vulnerables con respecto a su integración al mercado laboral. La inclusión laboral en una empresa debe ser tomada como un factor para el crecimiento de la organización. Tener capacidades diferentes nunca debe de ser un factor para que una persona no sea contratada, tampoco su estatus social o las circunstancias adversas que pueden presentarse en su vida personal. Realizar inclusión laboral de personas con discapacidad es el primer paso, pero es necesario comprender la necesidad de trabajar para mejorar su calidad su vida y mejorar el nivel de auto estima para lograr productividad y competitividad. El mayor número de personas con discapacidad son del sexo femenino, de hasta 29 años de edad, estado civil en su mayoría solteras, y el resto casadas o separadas. Su nivel de estudios es técnico o bachiller, su contrato dentro de la empresa es indeterminado en su gran mayoría, con una jornada de tiempo completo, ocupando gran parte de ellos los puestos de mando medio. El tipo de discapacidad de gran parte de los sujetos de estudio, son de tipo físico y el grado de discapacidad en el $50 \%$ de ellos es de un $25 \%$.

En la Variable 1) Actividad Física y Deporte de trabajadores con discapacidad como generador de estilos de vida saludable, los resultados muestran que existe gran interés por la actividad física y deporte por parte de este tipo de trabajadores, por lo que lo practican muy frecuentemente. El motivo de su práctica es porque quieren estar en buenas condiciones físicas considerando su estado, lo cual indica que no desean que su problemática siga avanzando. Normalmente buscan instalaciones que se adapten a sus condiciones físicas y de preferencia cerca de su casa o trabajo. 
Estos resultados hacen ver que al parecer la actividad física y deporte para las personas con discapacidad les permite sentirse bien y mantenerse en forma física de manera buena o aceptable. En referencia a la Variable 2) Integración socio-laboral de trabajadores con discapacidad, de acuerdo a las opiniones de las personas con discapacidad sujetos de estudio, se valora su contribución al desarrollo de la empresa, pone atención a sus objetivos y metas personas, y muy frecuentemente está dispuesta a ayudarle a que realice bien su trabajo. Se preocupa por darle actividades interesantes y que le den satisfacción al momento de realizarlas.

Los resultados muestran que las actuales ofertas de cualificación basadas únicamente en la dimensión técnica están demostrando ser insuficientes en los procesos de inserción socio-laboral. Ello es debido fundamentalmente al cambio permanente en el mercado de trabajo que exige a los empleados poner mucho esfuerzo en el ajuste de sus habilidades socio-laborales. Como conclusiones del trabajo realizado, diremos que que es importante que aquellas empresas que practican inclusión, adopten como parte de sus estrategias de gestión, programas de actividad física y deporte que ayude a conseguir y mantener hábitos saludables de la vida de sus trabajadores con discapacidad y modificar, al mismo tiempo la mejorara en la calidad de vida. La práctica deportiva en colectivos especiales es perdurable por los beneficios tanto a nivel físico-biológico como social y/o psicológico. (Riaño, Rodríguez y Álvarez, 2014).

Hay evidencia de tipo teórica que nos indica que ejercicio físico tiene una fuerte influencia en factores que no se habían considerado anteriormente. Véase estados Emocionales como ansiedad y depresión, disminución del estrés, mejoras de las capacidades intelectuales y cognitivas, apoyados en cambios funcionales a partir de la práctica de actividad física y deporte. Esto implica que la actividad deportiva puede considerarse un elemento central y fundamental en los programas de promoción de la calidad de vida de los trabajadores con discapacidad para la mejora de la inclusión laboral. La trascendencia de este tema y la importancia del mismo para la sociedad civil es un impulso para que las personas con necesidades específicas desarrollen actividades física y deporte, en la línea de otros estudios como los de (Torralba, Braz, \& Rubio, 2014)

En síntesis, podríamos concluir, según los resultados obtenidos en esta investigación, que el proceso de inserción en el empleo ordinario, ha colaborado en mejorar la percepción subjetiva de las personas con discapacidad en relación a su autodeterminación y bienestar emocional y material, pero no ha mejorado su participación social. En cuanto al funcionamiento de los apoyos y su funcionalidad, se necesita una mayor planificación y coordinación ajustada a las características de 


\section{http://revistainvestigacionacademicasinfrontera.com}

estas personas y al funcionamiento de cada unidad, para favorecer, no solo el desarrollo, bienestar y promoción de estas personas, sino también una mejora en el clima laboral.

Estos resultados comprueban el objetivo planteado en la investigación donde se hace ver desde la perspectiva del trabajador con discapacidad en empresas incluyentes, que la actividad física y el deporte, genera un estilo de vida saludable que les facilita la integracion socio - laboral en la empresa. La realización de este proyecto se considera viable ya que Sonora, cuentan con un sector económico muy dinámico en sus diferentes sectores, tanto el industrial, el comercial y el de servicios. Para Sonora, la inclusión es un nuevo reto dentro del sector empresarial. En esta investigación se pretende demostrar que existe una alta necesidad de realizar más trabajos de investigación relacionados con el tema, con enfoques específicos por sector, región y actividad, así como darlos a conocer a todas aquellas personas involucradas en la integración socio laboral de personas con discapacidad.

De la misma manera es necesario dejar claro que la metodología aplicada en este estudio podrá ser utilizada y ampliada en el proceso de la misma investigación y en otros casos. Los avances de resultados de este trabajo servirán para orientar a las empresas y personas con discapacidad para orientar su calidad de vida con el uso de la actividad física y el deporte como herramienta en la integración socio laboral. También serán útiles para un estudio cuantitativo posterior más amplio, el cual abarcará más empresas locales y permitirá obtener información sobre otras poblaciones en el estado o nacionales. 


\section{Referencias bibliográficas}

Chowdhury, M. y Benson, B. A. (2011). Deinstitutionalization and quality of life of individuals with intellectual disability: a review of the international literature. Journal of Policy and Practice in Intellectual Disabilities, 8(4), pp. 256-265.

Claes, C., Geert Van Hove, S., Vandevelde, J., and Schalock, R. (2012). The influence of support strategies, environmental factors, and client characteristics on quality of life-related personal outcomes. Research in Developmental Disabilities, 33(1), pp. 96-103.

Cobas Náñez, K. (2015). Desarrollo de estrategia de inclusión para personas con discapacidad al campo laboral. Tesis de Maestría en ciencias con orientación en gestión e innovación del diseño. Universidad Autónoma de Nuevo León, Facultad de Arquitectura, Monterrey, Nuevo León.

CONAPRED. (s.f.). Guía para Empleadores Interesados en la Inserción Laboral de Personas con Discapacidad. En CONAPRED, Guía para Empleadores Interesados en la Inserción Laboral de Personas con Discapacidad (pag. 11).

Consejo Nacional para las Personas con Discapacidad (2010). Programa Nacional para el Desarrollo de las Personas con Discapacidad 2009-2012, pp. 11. Consultado el 5 de octubre de 2018 en: http://www.educacionespecial.sep.gob.mx/pdf/issuu/pronaddis_2009_2012.pdf

Diario Oficial de la Federación (2014). Programa Nacional de Trabajo y Empleo para las Personas con Discapacidad 2014-2018. Consultado el 20 de octubre de 2018 en: http://www.dof.gob.mx/nota_detalle_popup.php?codigo=5342489

Fernández, J. (2008). La investigación en educación especial. Líneas temáticas y perspectivas de futuro. Perfiles educativos [online], 30, pp. 7- 32.

Ferrante, C. (2014). Cuerpo, discapacidad y estigma en el origen del campo del deporte adaptado de la Ciudad de Buenos Aires, 1950-1961: ¿una mera interiorización de una identidad devaluada? História, Ciências, Saúde - Manguinhos, Rio de Janeiro, 21(2), 421-437.

Gómez, L.E., Verdugo, M.A. Arias, B., Navas, P. y Schalock, R.L. (2013). The development and use of Provider Profiles at the organizational and systems level. Evaluation and Program Planning Vol. 40, pp. 17-26. 


\section{http://revistainvestigacionacademicasinfrontera.com}

Muñoz Jiménez, E. M., Garrote Rojas, D. y Sánchez Romero, C. (2017). La práctica deportiva en personas con discapacidad: motivación personal, inclusión y salud. International Journal of Developmental and Educational Psychology, vol. 4, núm. 1, 2017, pp. $145-152$

OMS (2011). Informe mundial sobre la discapacidad. Educación. Retrieved from http://who.int/disabilities/world_report/2011/summary_es.pdf

OMS (2013). Informe mundial la discapacidad. Convergencia Educativa.

Organización Internacional del Trabajo (2015). Estrategia y plan de acción para la inclusión de la discapacidad 2014-2017. Un doble enfoque de acciones transversales y especí cas para las personas con discapacidad . Organización internacional del Trabajo. - Ginebra: OIT, 2015 , ISBN 978-92-2-329423-6 . Consultado el 12 de octubre de 2017 en: http://www.ilo.org/wcmsp5/groups/public/---ed_emp/--ifp_skills/documents/genericdocument/wcms_370773.pdf

Pelayo Pérez, M. B. (2012). Capital social y competencias profesionales: Factores condicionantes para la inserción laboral. Disponible en http://www.eumed.net/

Riaño-Galán, A. M., Rodríguez-Martín, A., Ruíz-García, R. y Álvarez-Arregui, E. (2014). La transición a la vida activa de las personas con discapacidad: expectativas familiares y grado de ajuste al trabajo. Revista Brasileira de Educação Especial, 20(2), pp. 283-302

Segura, J., Martínez-Ferrer, J. O., Guerra, M. y Barnet, S. (2013). Creencias sobre la inclusión social y el deporte adaptado de deportistas, técnicos y gestores de federaciones deportivas de deportes para personas con discapacidad. Revista Iberoamericana de Psicología Del Ejercicio y El Deporte, 8(1), 120-144.

Torralba, M. A., Braz, M. y Rubio, M. J. (2014). La motivación en el deporte adaptado Motivation in adapted sport. Phychology, Society \& Education, 6(1), 27-40. 
Walker, H.M., Calkins, C., Wehmeyer, M.L., Bacon, A., Palmer, S.B., Jesien, G.S., (2011). A socio- ecological approach to promote self-determination. Exceptionality: A Special Education Journal, 19(1), 6-18.

\section{Como citar este articulo}

María Julia León Bazan, Gricelda Henry Mejia, Nidia Carolina Barahona Herrejon. La actividad Física y el deporte como estilo de vida para la integración socoio-laboral de empleados con discapacidad. RIASF. Núm. 28, Julio-diciembre (2018), ISSN 2007-8870. pp. $\mathbf{X X}-\mathbf{X X}$. 